\title{
ANALISIS BANTUAN HIBAH BIBIT SAMBUNG PUCUK TERHADAP PERUBAHAN PERILAKU PETANI KAKAO DI KABUPATEN PINRANG
}

\section{(Analysis of Chupon Grafting Grand Aid on the Behavior of Cocoa Farmers in Pinrang Regency)}

\author{
Andi Yuli Tenriawaru ${ }^{1}$, Nurliani Karman² dan Nuraeni \\ ${ }^{1}$ Pascasarjana Universitas Muslim Indonesia \\ E-mail : chaken27@gmail.com \\ ${ }^{2}$ Program Studi Agribisnis Fakultas Pertanian Universitas Muslim Indonesia Makassar
}

\begin{abstract}
Analysis Of Chupon Grafting Grand Aid On The Bahavior Of Cocoa Farmers in Pinrang Regency. The research was conducted in June2017 - August 2017 on Duampanua District Pinrang Regency.The purpose of this study was to describe and identify the implementation of chupon grafting aid program in Pinrang Regency, to analyze the level of knowledge and skill of farmers on the assistance of chupon grafting aid program of cocoa sedling, and the participation of the cocoa farmers in the farmer group in Pinrang Regency. This research uses descriptive qualitative method with interview technique to explore information about chupon grafting cacao seedlings, and survey approach to describe the aid pattern, and include several stages of data collection and field observation, data analysis and data processing. The results showed that with the help of chupon grafting affect the behavior of farmers in the form of increased knowledge, skills and participation in farmer groups. Assistance given has been in accordance with the flow of mechanisms that have been in accordance with the Minister of Home Affairs Regulation of the Minister of Home Affairs No. 30 of 2012 and South Sulawesi Governor Regulation No. 55 of 2012.
\end{abstract}

Keywords : Grand aid, Chupon Grafting, Cocoa, Farmer behavior, Farmer empowerment and Coca Farming

\section{PENDAHULUAN}

Tanaman kakao (Theobroma cacao L) merupakan salah satu komoditas andalan perkebunan yang peranannya cukup penting bagi perekonomian nasional, khususnya sebagai penyedia lapangan kerja, sumber pendapatan dan devisa negara. Pada Tahun 2002 perkebunan kakao telah menyediakan lapangan kerja dan sumber pendapatan bagi sekitar 900 ribu petani yang sebagian besar berada di Kawasan Timur
Indonesia, serta memberikan sumbangan devisa terbesar setelah karet dan kelapa sawit dengan nilai sebesar US \$ 701 juta (Anonim, 2005).

Mutu kakao rakyat di Indonesia masih cukup rendah, padahal bila dilihat dari segi jumlah adalah yang terbesar, sehingga masalah mutu kakao pun menjadi faktor paling menonjol dan dan menjadi kendala utama dalam skala nasional (Puslitkoka, 2010). Hal ini terjadi karena Indonesia memiliki kelemahan 
yakni produktivitas yang dihasilkan rendah dan kualitasnya yang kurang memuaskan. Pemicu terjadinya kelemahan ini yaitu adanya proses fermentasi yang tidak benar. Kekurangan lainnya adalah biji-biji kakao yang berjamur dan berserangga akibat gudang penyimpanan yang kurang memadai. Hal inilah yang membuat citra kakao di pangsa pasar dunia menjadi kurang menguntungkan (Susanto, 1994). Bersandar pada permasalahan tersebut maka diupayakan beberapa perbaikan baik dari segi teknis maupun kualitas sumber daya manusianya yang merupakan faktor penting dalam peningkatan produksi serta produktivitas tanaman kakao.

Kakao merupakan salah satu komoditi unggulan yang ada di Sulawesi Selatan, dimana komoditi ini masuk dalam target capaian Dinas Perkebunan Provinsi Sulawesi Selatan yakni peningkatan produksi kakao sebesar 200.000 ton sampai dengan Tahun 2018. Potensi kakao di Sulawesi Selatan terbilang strategis, baik dari segi luasan yang dimiliki petani sampai kepada besarnya minat masyarakat untuk menanam kakao, disamping banyaknya pilihan karakter kakao di Indonesia. Melihat besarnya potensi yang dimiliki, maka pemerintah daerah
Sulawesi Selatan melalui kebijakan gubernur mencanangkan program prioritas pembagian bibit gratis melalui bantuan hibah yang dinilai akan mampu memacu pembangunan perkebunan. Pembagian bibit ini termasuk kakao sebagai komoditi unggulan Sulawesi Selatan yang menjadi target peningkatan produksi. dan produktivitas tanaman perkebunan, yang dialokasikan sejak Tahun 2012 hingga saat ini. Besarnya antusias petani kakao dalam menerima bantuan ini menimbulkan problem baru yang mengemuka dan terjadi di masyarakat yakni munculnya ketergantungan dari para petani akan bantuan yang diberikan, sehingga tanpa sadar mereka "terlena" dengan segala kemudahan dan sarana prasarana yang diberikan dan cenderung hanya bekerja jika ada bantuan, tanpa munculnya kesadaran untuk mampu berswadaya secara mandiri dalam mengelola lahan perkebunan mereka sendiri. Dari sinilah terlihat bahwa pola bantuan semacam ini memang menguntungkan dari segi ekonomi petani, dimana mereka memiliki keterbatasan dalam permodalan, namun dari segi mental dan perilaku petani menjadi tidak mandiri. Motivasi dan semangat berusahatani menurun jika tidak ada 
bantuan. Chambers Roberts (1993)

berpendapat bahwa paradigma yang dominan digunakan lebih berbasis pada transfer teknologi, dan bukan pada orangnya maupun proses belajarnya. Pendekatan yang tidak mengutamakan manusianya ini ternyata menghasilkan ketergantungan yang tinggi oleh daerah kepada pusat dan terkotak-kotak antara sub sektor dalam agribisnis dan tidak sinergis.

\section{METODE PENELITIAN}

\section{Lokasi dan Waktu}

Penelitian dilakukan di Kecamatan Duampanua Kabupaten Pinrang Provinsi Sulawesi Selatan. Penelitian ini dilaksanakan mulai bulan Juni 2017 sampai dengan Agustus 2017.

\section{Pengumpulan Data}

Teknik yang digunakan untuk untuk memperoleh data yang diperlukan yaitu wawancara terstruktur dengan menggunakan kuesioner, yang dilakukan terhadap 80 petani dari 16 kelompok tani, dimana masing-masing dipilih 5 (lima) orang secara random yang mewakili kelompok taninya.

\section{Analisis Data}

Penelitian ini menggunakan metode deskriptif kualitatif. Paramater yang diteliti dalam penulisan ini adalah tingkat pengetahuan petani terhadap adanya teknologi sambung pucuk ini, keterampilan dalam mengelola tanaman kakao hasil sambung pucuk dan tingkat keaktifan petani dalam suatu wadah kelompok tani serta tingkat efektivitas pengadaan pola bantuan hibah ini. Skala pengukuran yang akan dipakai dalam penelitian ini adalah skala likert, yaitu skala yang digunakan untuk mengukur sikap, pendapat, dan persepsi seseorang atau sekelompok orang tentang fenomena sosial. Dengan Skala Likert, variabel yang akan diukur dijabarkan menjadi indikator variabel. Kemudian indikator tersebut dijadikan sebagai titik tolak untuk menyusun item-item instrumen yang dapat berupa pertanyaan atau pernyataan Jawaban setiap item instrumen menggunakan Skala Likert yakni antara $1-5$, dimana $1=$ tidak tahu, $2=$ kurang tahu, 3 = Ragu-ragu, 4 = Tahu, $5=$ Sangat tahu.

Untuk mendapatkan nilai skoring yang dilakukan terhadap 80 responden mengenai tingkat pengetahuan petani, keterampilan petani serta partisipasi dalam 
kelompok tani, dapat dilakukan dengan No 30 Tahun 2012 dan Peraturan interval sebagai berikut :

Gubernur Sulawesi Selatan No 55 Tahun

- 336 - 399 = Sangat tahu/ Sangat 2012, dalam rangka memenuhi program terampil/ Sangat aktif

- $272-335=$ Tahu/ Terampil / Aktif prioritas Gubernur Sulawesi Selatan telah

- 208 - 271 = Ragu-ragu/ Cukup terampil dirasakan manfaatnya untuk kesejahteraan / Cukup aktif masyarakat.

Adapun indikator capaian

- $144-207$ = Kurang tahu/ Kurang terampil/ Kurang aktif

- $80-143=$ Tidak tahu/ Tidak terampil/Tidak aktif

\section{HASIL DAN PEMBAHASAN}

\section{Pelaksanaan Program Bantuan Hibah}

Pelaksanaan bantuan hibah sambung pucuk di Kabupaten Pinrang telah berjalan sesuai mekanisme yang telah disyaratkan melalui Peraturan Menteri Dalam Negeri pelaksanaan bantuan hibah yang efektif yaitu adanya dokumen berupa ; proposal, pakta integritas, surat pernyataan bersedia diaudit, surat pernyataan domisili serta memenuhi alur mekanisme yang telah ditetapkan. Selain itu adanya petunjuk teknis paket teknologi budidaya bibit sambung pucuk juga merupakan bagian dari efektifitas kegiatan.

\section{Analisis Tingkat Pengetahuan Petani}

Tabel 1. Rata-rata Tingkat Pengetahuan Petani Penerima Bantuan Hibah Sambung Pucuk Kakao.

\begin{tabular}{clll}
\hline No & \multicolumn{1}{c}{ Indikator } & Nilai Skor & Kategori \\
\hline 1 & Dapat membedakan bibit layak salur dan tidak & 345 & Sangat tahu \\
2 & Mengetahui syarat-syarat bibit kakao yg baik & 342 & Sangat tahu \\
3 & Dapat membedakan bibit asalan dengan bukan & 299 & Tahu \\
4 & Mengetahui proses penyambungan bibit kakao samcuk & 364 & Sangat tahu \\
5 & Mengetahui keunggulan tanaman kakao samb.pucuk & 343 & Sangat tahu \\
6 & Mengetahui tentang sertifikasi benih & 335 & Tahu \\
7 & Membedakan tan kakao samb pucuk dengan yg bukan & 361 & Sangat tahu \\
8 & Mengetahui teknik pemangkasan & 270 & Ragu-ragu \\
9 & Melakukan penyiapan lahan sesuai petunjuk teknis & 319 & Tahu
\end{tabular}



Perilaku Petani Kakao di Kabupaten Pinrang

\begin{tabular}{llll}
\hline No & \multicolumn{1}{c}{ Indikator } & Nilai Skor & Kategori \\
\hline 10 & Melakukan penanaman sesuai waktu tanam & 362 & Sangat tahu \\
11 & Mengetahui pengelolaan penaung yang benar & 317 & Tahu \\
12 & Melakukan pengendalian gulma yang benar & 360 & Sangat tahu \\
13 & Melakukan pemupukan sesuai petunjuk teknis & 341 & Sangat tahu \\
14 & Melakukan pemupukan sesuai waktu anjuran & 332 & Tahu \\
15 & Mengetahui jenis pupuk yang meningkatkan produksi & 306 & Tahu \\
16 & Mengetahui tentang pupuk organik & 370 & Sangat tahu \\
17 & Mengetahui manfaat pupuk organik & 336 & Sangat tahu \\
18 & Memahami adopsi teknologi untuk meningkatkan prod. & 346 & Sangat tahu \\
19 & Mendapatkan pengetahuan baru ttg budidaya kakao & 350 & Sangat tahu \\
20 & Mengetahui teknik lain selain sambung pucuk & 359 & Sangat tahu \\
\hline & Total & $\mathbf{6 . 8 4 6}$ & \\
\end{tabular}

Sumber : Data Primer Setelah Diolah, 2017

Tabel 1 menunjukkan bahwa dari 80 responden yang dijadikan sampel dalam penelitian ini, sebahagian besar telah memiliki pemahaman dan pengetahuan memadai tentang sambung pucuk. Hal ini dilihat dari rata-rata dari 20 pertanyaan memiliki kategori sangat tahu yakni 337,85 dari total 6.757 Ada 5 indikator yang memiliki kategori tahu yakni, untuk indikator pertanyaan ke 3, 6, 9, 11,14 dan 15. Hal ini menunjukkan responden telah memiliki pengalaman dalam membedakan antara bibit asalan dengan bibit yang telah melalui proses sertifikasi. Terlihat pula adanya tingkat keraguan-raguan responden pada indikator 8 mengenai teknik pemangkasan, mengingat proses pemangkasan ini sering diabaikan sebagai bagian dari pemeliharaan. Responden masih terpaku pada upaya peningkatan produksi, namun mengabaikan teknis pemangkasan. Dalam melakukan pemangkasan, petani juga masih terkendala pada adanya alat-alat pemangkasan. 


\section{Analisis Tingkat Keterampilan Petani}

Tabel 2. Rata-rata Tingkat Keterampilan Petani Kakao Sambung Pucuk

\begin{tabular}{|c|c|c|c|}
\hline No & Indikator & Nilai Skor & Kategori \\
\hline 1 & Mengetahui teknis penyambungan sambung pucuk & 328 & Terampil \\
\hline 2 & Menguasai teknik penanaman & 335 & Terampil \\
\hline 3 & Menguasai cara penyulaman & 326 & Terampil \\
\hline 4 & Dapat melakukan penyambungan sambung pucuk & 335 & Terampil \\
\hline 5 & Dapat melakukan pemindahan bibit ke pesemaian & 360 & Sangat terampil \\
\hline 6 & Melakukan pemeliharaan pasca penanaman & 371 & Sangat terampil \\
\hline 7 & Mengidentifikasi kakao yg layak utk dipindahkan & 362 & Sangat terampil \\
\hline 8 & Dapat melakukan pemangkasan & 200 & Kurang terampil \\
\hline 9 & Dapat melakukan sanitasi blok & 235 & Cukup terampil \\
\hline 10 & Melakukan pemupukan sesuai dosis & 312 & Terampil \\
\hline 11 & Terampil mengelola penaung & 291 & Terampil \\
\hline 12 & Menguasai pengendalian OPT yang benar & 331 & Terampil \\
\hline 13 & Melakukan penyiangan kebun dengan benar & 317 & Terampil \\
\hline 14 & Melakukan pengendalian sesuai serangan & 308 & Terampil \\
\hline 15 & Melakukan teknis penjarangan buah & 279 & Terampil \\
\hline 16 & Mengikuti sekolah lapang & 329 & Terampil \\
\hline 17 & Melakukan pengolahan tanah dengan benar & 319 & Terampil \\
\hline 18 & Melakukan pengamatan rutin terhadap OPT & 207 & Kurang terampil \\
\hline 19 & Melakukan aplikasi pemupukan yang benar & 316 & Terampil \\
\hline 20 & Melakukan pengendalian gulma dengan benar & 326 & Terampil \\
\hline & Total & 6.187 & \\
\hline & Rata-rata & 309,35 & Terampil \\
\hline
\end{tabular}

Sumber : Data Primer Setelah Diolah, 2017

Tabel 2 menyajikan bahwa keterampilan dalam melakukan teknis reponden sebanyak 80 orang yang dipilih sambung pucuk pada tanaman kakao. Hal secara random dengan tingkat usia, ini ditunjukkan dengan besarnya total skor pendidikan serta latar belakang yang yang dimiliki yakni 6.187 atau rata-rata berbeda, ternyata mampu dan memiliki 309,35 dengan kategori "terampil". 


\section{Tingkat Partisipasi Kelompok Tani}

Tabel 3. Rata-rata Tingkat Partisipasi Kelompok Tani Kakao Sambung Pucuk di Kabupaten Pinrang

\begin{tabular}{clcl}
\hline No & \multicolumn{1}{c}{ Indikator } & Nilai Skor & \multicolumn{1}{c}{ Kategori) } \\
\hline 1 & Memahami peran dalam keanggotaan KT & 326 & Aktif \\
2 & Berperan aktif dalam setiap kegiatan KT & 341 & Sangat aktif \\
3 & Melakukan koordinasi sesame anggota & 280 & Aktif \\
4 & Mengetahui program bantuan yg pernah diikuti KT & 306 & Aktif \\
5 & Bekerjasama baik sesama anggota & 312 & Aktif \\
6 & Aktif dalam penyusunan proposal & 323 & Aktif \\
7 & Bekerjasama dgn ketua kelompok & 303 & Aktif \\
8 & Memahami teknis penyusunan proposal & 252 & Cukup aktif \\
9 & Memahami tujuan dan sasaran bantuan hibah & 258 & Cukup aktif \\
10 & Berperan dalam pertemuan Gapoktan & 339 & Sangat aktif \\
11 & Aktif dalam memberikan masukan dlm kelompok & 303 & Aktif \\
12 & Merasakan adanya perubahan pola pikir & 309 & Aktif \\
13 & Rutin mengikuti pertemuan & 301 & Aktif \\
14 & Mampu bersama dalam memecahkan masalah & 309 & Aktif \\
15 & Memahami tujuan didirikannya KT & 259 & Cukup aktif \\
16 & KT yg diikuti mampu memberikan motivasi & 330 & Aktif \\
17 & Merasa dilibatkan dalam pengambilan keputusan & 300 & Aktif \\
18 & Memahami tugas dan fungsi dalam KT & 305 & Aktif \\
19 & Berpartisipasi dalam kegiatan kelompok & 271 & Cukup aktif \\
20 & Mengetahu pembagian peran anggota dlm KT & 296 & Aktif \\
\hline & TOTAL & $\mathbf{6 . 0 2 3}$ & \\
& Rata-rata & $\mathbf{3 0 1 , 1 5}$ & Aktif \\
\hline & : Data Primer Setelah Difah, & &
\end{tabular}

Sumber : Data Primer Setelah Diolah, 2017

Tabel 3 menunjukkan bahwa rata- pada jumlah indikator pertanyaan yang rata tingkat partisipasi kelompok tani diajukan, sebagian besar merupakan berada dalam kategori aktif yakni sebesar kategori 'aktif'. Utamanya pada indikator 301,15 dari total 6.023. Hal ini ke 2 mengenai peran aktif anggota yang menunjukkan bahwa adanya bantuan memiliki skor tertinggi dibanding hibah sambung pucuk tanaman kakao indikator lainnya yakni 341. Selanjutnya meningkatkan partisipasi petani kakao di pada indikator ke 10 mengenai peranan Kabupaten Pinrang. Hal ini didasarkan responden dalam kelompok tani yang 
sangat aktif dalam gapoktan dengan skor setiap kegiatan yang diadakan kelompok 339. Berdasarkan hal tersebut, maka tani, yang tercermin pada indikator dapat diyakini bahwa setiap anggota pertanyaan ke 17 dengan skor 300 atau kelompok senantiasa dilibatkan dalam masuk dalam kategori aktif.

Tabel 4. Rekapitulasi Rata-rata Bantuan Hibah Sambung Pucuk terhadap Perubahan Pengetahuan, Keterampilan dan Partisipasi Penerima Bantuan Hibah di kabupaten Pinrang

\begin{tabular}{clc}
\hline No & \multicolumn{1}{c}{ Uraian } & Kategori \\
\hline 1 & Bantuan hibah sambung pucuk & Efektif \\
2 & Pengetahuan petani & Sangat tahu \\
3 & Keterampilan petani & Terampil \\
4 & Partisipasi petani dalam kelompok tani & Aktif \\
\hline
\end{tabular}

Sumber : Data Primer Setelah Diolah, 2017

Berdasarkan hasil analisis deskriptif diberikan ini telah berjalan efektif dan dapat diketahui bahwa hasil rekapitulasi sesuai alurnya. rata-rata atas indikator bantuan hibah, tingkat pengetahuan, keterampilan dan partisipasi petani dalam kelompok tani menunjukkan indikasi positip . Adanya bantuan hibah sambung pucuk pada tanaman kakao dapat memberikan pemahaman kepada petani mengenai mekanisme bantuan hibah yang benar, sesuai dengan Peraturan Menteri Dalam Negeri Peraturan Menteri Dalam Negeri No 30 Tahun 2012 dan Peraturan Gubernur Sulawesi Selatan No 55 Tahun 2012, dalam rangka memenuhi program prioritas Gubernur Sulawesi Selatan telah dirasakan manfaatnya untuk kesejahteraan masyarakat. Dimana bantuan yang
Bantuan hibah ini juga mampu meningkatkan pengetahuan petani mengenai teknis penyambungan pada tanaman kakao yang baik dan benar, serta pemeliharaan lainnya pasca pemindahan tanaman ke lahan pertanaman. Paketpaket yang termasuk dalam bagian bantuan hibah ini terbukti dapat meningkatkan pengetahuan petani yakni sarana prasarana yang diberikan sebagai bagian dari pengawalan pelaksanaan kegiatan bantuan hibah ini termasuk adanya sekolah lapang, agar tepat sasaran.

Peningkatan keterampilan petani juga terlihat dari adanya bantuan hibah sambung pucuk ini, yang dianggarkan 
pemerintah sebagai bagian dari upaya untuk meningkatkan produksi serta produktivitas tanaman kakao di Sulawesi Selatan. Dari mulanya petani hanya mengandalkan bantuan untuk meningkatkan usaha kebunnya, beralih pada perubahan pola pikir dan sikap menjadi petani petani mandiri yang mampu melakukan upaya sambung pucuk pada tanaman kakaonya sendiri. Tentunya kedepannya diharapkan akan lebih berkembang, dengan menjadikan Kabupaten Pinrang khususnya di Kabupaten Duampanua sebagai kebun sumber benih kakao, seperti yang telah ada di kabupaten sentra kakao lainnya.

Partisipasi petani dalam kelompok tani juga menjadi aktif khususnya dalam peran partisipasi petani dalam kegiatankegiatan yang dilakukan kelompok tani, termasuk dalam penyusunan proposal yang merupakan langkah awal turunnya kegiatan bantuan hibah ini. Sehingga petani tidak lagi menjadi objek penerima manfaat yang tergantung pada pemberian dari pihak luar seperti pemerintah, melainkan dalam posisi sebagai subjek (agen atau partisipan yang bertindak) yang berbuat secara mandiri. Berbuat secara mandiri bukan berarti lepas dari tanggung jawab negara. Masyarakat yang mandiri dapat di artikan sebagai masyarakat yang memiliki kapasitas dalam mengembangkan potensi dan sumberdayanya sendiri, menyelesaikan masalah secara mandiri, dan ikut menentukan arah kehidupannya yang lebih positip.

\section{KESIMPULAN}

Berdasarkan hasil penelitian yang dilakukan maka dapat disimpulkan antara lain:

1. Pelaksanaan bantuan hibah sambung pucuk pada tanaman kakao di Kabupaten Pinrang telah berjalan sesuai mekanisme serta prosedur yang telah ditetapkan sesuai Peraturan Gubernur Sulawesi Selatan Nomor 55 Tahun 2012 tentang Perubahan atas peraturan Gubernur Sulawesi Selatan Nomor 77 Tahun 2011 Tentang Tata Cara Penganggaran, Pelaksanaan dan Penatausahaan, Pertanggungjawaban dan Pelaporan serta Monitoring dan Evaluasi Belanja Hibah dan Bantuan Sosial yang bersumber dari Anggaran Pendapatan dan Belanja Daerah Provinsi Sulawesi Selatan dan Peraturan Menteri Dalam Negeri Nomor 39 Tahun 2012, tentang Perubahan atas Peraturan Menteri 
Dalam Negeri Nomor 32 Tahun 2011

Tentang Pedoman Pemberian Hibah dan Bantuan Sosial yang bersumber dari anggaran pendapatan dan belanja daerah. Paket bantuan yang diberikan termasuk sarana dan parasarananya dinilai efektif untuk mampu meningktkan tingkat kehidupan dan pendapatan petani kearah yang lebih baik.

2. Tingkat pengetahuan petani responden terhadap adopsi teknologi kakao sambung pucuk termasuk dalam kategori sangat tahu.

3. Tingkat keterampilan petani kakao mengenai sambung pucuk di Kabupaten Pinrang berada dalam kategori terampil.

4. Tingkat partisipasi petani dalam kelembagaan kelompok tani tinggi di Kabupaten Pinrang berada dalam kategori aktif.

\section{DAFTAR PUSTAKA}

Adi Prawoto, 2007. Pedoman Teknis Budidaya Kakao (Theobroma cacao $L$ ), Puslitkoka Indonesia Jember

Allport, G W.1954 The Nature of

Prejudice Oxford: Addision Wesley. Anonim, 2005. Badan Penelitian dan Pengembangan Pertanian Departemen Pertanian.
Anonim, 2014a. Teknik Sambung Pucuk pada Budidaya Kakao, Riki Mulya Blok Spot

Anonim , 2014b. Mengenal Tanaman Kakao. Direktorat Jenderal Perkebunan

Anonim , 2014c. Budidaya Tanaman Kakao. Direktorat Jenderal Perkebunan

Anonim, 2016. Buku Putih Sanitasi . Pokja AMPL Kab. Pinrang

Buku Pintar Budidaya Kakao , 2010. Pusat Penelitian Kopi dan Kakao (Puslitkoka). Agro Media Pustaka.

Cocoinfo,2012. Kakao dan Budidaya, Direktorat Jenderal Perkebunan

Dinas Perkebunan Provinsi Sulawesi Selatan, 2010. Laporan Serangan OPT Penting Tanaman Perkebunan Provinsi Sulawesi Selatan. Dinas Perkebunan Provinsi Sulawesi Selatan. Makassar

Debby Handayani, 2013. Naskah Publikasi Manajemen Dana Bantuan Hibah, Tanjung Pinang.

Dwi Sadono, Maret 2008, Jurnal penyuluhan, Instiut Pertanian Bogor

Elna Karmawati, Zainal Mahmud, M. Syakir, dkk, 2010. Budidaya dan Pasca Panen Kakao, Litbang Perkebunan

Friedman, Jhon, 1992. Empowerment The Politics of Alternative Development Blackwell Publishers, Cambidge USA 
FX. Susanto, 1994. Tanaman Kakao Budidaya dan Pengolahan Hasil, Penerbit Kanisius

Hendrik Prayitno, 2007. Jurnal Analisis Pengaruh Dana Hibah Prestasi Terhadap Pendapatan Anggota Kelompok Pengembangan Partisipasi Lahan Kering Terpadu di Kabupaten Lumajang

Juknis Bantuan Hibah, 2016. Dinas Perkebunan Provinsi Sulawesi Selatan

Mariyah, 2009. Jurnal Pengaruh Bantuan Pinjaman Langsung Masyarakat Terhadap Perndapatan dan Efisiensi Usahatani Padi Sawah di Kabupaten Penajam Paser

Mosher, AT. 1965. Menggerakkan dan Membangun Pertanian. CV. Yasaguna Jakarta

Mubarak, Z. 2010. Evaluasi Pemberdayaan Masyarakat Ditinjau Dari Proses Pengembangan Kapasitas Pada Program PNPM Mandiri Perkotaan Di Desa Sastrodirjan Kabupaten Pekalongan. Tesis. Program Studi Magister Teknik Pemberdayaan Wilayah Dan Kota. Undip. Semarang.

Nelfita Rizka, Salmiahdan Aspan Sofyan, 2015, Studi Kasus Analisis Dampak Penggunaan Dana Bantuan Program Optimalisasi Lahan dalam Meningkatkan Produksi Padi Sawah di Kabupaten Serdang

Ni KM Sri Marheni, I Ketut Kirya dan Ni Nyoman Yulianthini, 2012, Pengaruh Dana Bantuan Langsung Masyarakat (BLM) Terhadap Pendapatan Bersih Anggota Kelompok Nelayan, Singaraja.
Notoatmodjo, Soekidjo. 2003. Pendidikan Dan Perilaku Kesehatan . Rineka Cipta. Jakarta

Kelompok Kerja (Pokja),2016. Buku putih Sanitasi, Pinrang

Laporan Kinerja , 2015. Dinas Perkebunan Provinsi Sulawesi Selatan

Pasandaran, E. dan M.O. Adnyana. 1995. Peranan Balai Pengkajian Teknologi Pertanian (BPTP) dalam Meningkatkan Keterkaitan antara Peneliti dan Penyuluh. Makalah Lokakarya Dinamika dan Perspektif Penyuluhan Pertanian pada PJP II, 5 - 6 Juli 1995. Bogor.

Peraturan Menteri Dalam Negeri RI nomor 14 Tahun 2016, tentang Pedoman Pemberian Hibah dan Bantuan Sosial yang bersumber dari Anggaran Pendapatan dan Belanja Daerah

Pusat Penelitian Kopi dan Kakao Indonesia, 2010. Pedoman Teknis Budidaya Tanaman Kopi Indonesia. Pusat penelitian Kopi dan Kakao Indonesia. Jember, Jawa Timur.

Planck, Ulrich. 1990. Sosiologi Pertanian . Jakarta : Yayasan Obor Indonesia.

Robert Chambers, 1993. Participatory Rural Appraisal (PRA), Memahami Desa Secara Partisipatif. Oxfarm

Sasmita Siregar,dkk. 2013. Jurnal Peranan Program Pengembangan Usaha Agribisnis Pedesaan (PUAP) terhadap Peningkatan Pendapatan Petani. 
Sipahelut, Michel. 2010. Analisis Pemberdayaan Masyarakat Nelayan Di Kecamatan Tobelo Kabupaten Halmahera Utara. Tesis. IPB. Bogor.

Sukmaniar. 2007. Efektivitas Pemberdayaan Masyarakat Dalam Pengelolaan Program Pengembangan Kecamatan (Ppk) Pasca Tsunami Dikecamatan Lhoknga Kabupaten Aceh Besar. Tesis. UNDIP. Semarang.

Sulistiyani, Ambar Teguh, 2003. Manajemen Sumber Daya Manusia, Yogyakarta, Graha Ilmu

Sumadiningrat, Gunawan (2002) Pemberdayaan Masyarakat dan Jaring Pengamanan Sosial, Jogjakarta. Ghalia Indonesia

Susanto,1994. Tanaman Kakao, Budidaya dan Pengolahan Hasil, Penerbit Kanisius, Jogjakarta

Sutoro Eko,2002. Pemberdayaan Masyarakat Desa, Materi Diklat Pemberdayaan Masyarakat Desa, yang diselenggarakan Badan Diklat Provinsi Kaltim, Samarinda
Uphoff Uphoff, N. 1988. Menyesuaikan Proyek pada Manusia.dalam M.M. Cernea (eds). 1988.Mengutamakan Manusia di Dalam Pembangunan: Variabel - variabel Sosiologi di Dalam Pembangunan Pedesaan (Publikasi Bank Dunia). Penerjemah B.B. Teku. Jakarta: UI Press.

Yul Harry Bahar (2015) Jurnal Dampak Perilaku Petani dalam Budidaya Bawang Merah Terhadap Perubahan Kondisi Agroekosistem di Brebes. 